Vedmid' L. B., Dimitrov V. M., Fedorova 0. M.

\author{
L. B. Vedmid', V. M. Dimitrov, O. M. Fedorova \\ Institute of metallurgy, \\ Ural Branch of Russian Academy of Sciences, \\ 101 Amundsena st., Ekaterinburg, 620016, Russian Federation \\ elarisa100@mail.ru
}

\title{
Low-temperature synthesis under low oxygen pressure and thermodynamic properties of $\mathrm{YbFe}_{2} \mathrm{O}_{4-\delta}$
}

The mixed-valence compound $\mathrm{YbFe}_{2} \mathrm{O}_{4-\delta}$ was synthesized using a modified method that allows employing gaseous atmosphere with a controlled ratio of inert gas and oxygen. The stability range for $\mathrm{YbFe}_{2} \mathrm{O}_{4-\delta}$ was determined at $1090{ }^{\circ} \mathrm{C}$ under reducing conditions. Thermodynamic characteristics for the formation of $\mathrm{YbFe}_{2} \mathrm{O}_{4-\delta}$ from the simple oxides and from elements in the temperature range $700-910{ }^{\circ} \mathrm{C}$ have been calculated. The obtained results allow specifying the low-temperature part of $\mathrm{P}-\mathrm{T}-\mathrm{X}$ diagram for the $\mathrm{Yb}-\mathrm{Fe}-\mathrm{O}$ system.

Keywords: oxygen partial pressure, mixed-valence compound, thermodynamic properties, complex oxides, oxygen nonstoichiometry

Received: 27.11.2017. Accepted: 26.03.2018. Published: 10.05.2018.

(c) Vedmid' L. B., Dimitrov V. M., Fedorova 0. M., 2018

\section{Introduction}

Complex oxides $\mathrm{RFe}_{2} \mathrm{O}_{4}(\mathrm{R}=\mathrm{Er}$, $\mathrm{Tm}, \mathrm{Yb}, \mathrm{Lu})$, which demonstrate both ferroelectric and ferromagnetic properties, are presenting a special class of materials called multiferroics. These materials are promising for application in energy-saving and storage devices [1]. The information concerning physicochemical properties for these complex oxides is important for their synthesis and practical applications. One of the representatives of such materials is $\mathrm{YbFe}_{2} \mathrm{O}_{4}$.

Taking into account that $\mathrm{YbFe}_{2} \mathrm{O}_{4}$ contains iron in two oxidation states, $\mathrm{Fe}^{3+}$ and $\mathrm{Fe}^{2+}$, it is obvious that one of the important parameters for its synthesis is oxygen partial pressure in gaseous phase. Since the compound is stable only within narrow interval of temperature and oxygen partial pressure $[2,3]$, it is very important to es- tablish a synthesis protocol and to find the temperature and oxygen partial pressure ranges of its stability. Based on the ionic radii of rare earth ions $\mathrm{R}^{3+}$ [2], the whole set of R-Fe-O systems can be divided into four groups. The $\mathrm{Yb}-\mathrm{Fe}-\mathrm{O}$ system belongs to the forth group $\mathrm{D}$, in which $\mathrm{R}_{2} \mathrm{Fe}_{3} \mathrm{O}_{7}$ exists together with $\mathrm{RFeO}_{3}, \mathrm{R}_{3} \mathrm{Fe}_{5} \mathrm{O}_{12}$ and $\mathrm{RFe}_{2} \mathrm{O}_{4}$. The decrease of temperature may cause a decomposition of $\mathrm{R}_{2} \mathrm{Fe}_{3} \mathrm{O}_{7}$ and, as a result, the $\mathrm{Yb}-\mathrm{Fe}-\mathrm{O}$ system would be converted to the group C [4]. The synthesis of mixed-valence compounds in the $\mathrm{R}-\mathrm{Fe}-\mathrm{O}$ systems belonging to the $\mathrm{C}$ and $\mathrm{D}$ groups is traditionally performed under low oxygen partial pressure employing $\mathrm{H}_{2}$ and $\mathrm{CO}_{2}$ mixtures [2-4]. In works [2-4] raw mixtures of $\mathrm{R}_{2} \mathrm{O}_{3}$ and $\mathrm{Fe}_{2} \mathrm{O}_{3}$ were annealed at temperature $1200{ }^{\circ} \mathrm{C}$ in flow of gas with low oxygen activity. A precise 
control and maintenance of oxygen partial pressure in such gaseouse mixtures in contact with oxide sample is not an easy task. The information about the possibility of $\mathrm{YbFe}_{2} \mathrm{O}_{4}$ synthesis at temperatures lower than $1200^{\circ} \mathrm{C}$ is absent. The purpose

\section{Experimental}

$\mathrm{YbFe}_{2} \mathrm{O}_{4-\delta}$ was synthesized by the advanced method in which gas mixture of argon and oxygen was used. Reducing conditions were provided by maintaining the required value of oxygen partial pressure using the electrochemical method [5]. An interaction of a sample with the gaseous Ar- $\mathrm{O}_{2}$ mixture can only result in oxygen exchange, while using of $\mathrm{CO}_{2}-\mathrm{H}_{2}$ mixture may lead to the formation of carbides.

Preliminarily dried powders of $\mathrm{Fe}_{2} \mathrm{O}_{3}$ (purity $\geq 98 \%$ ) and $\mathrm{Yb}_{2} \mathrm{O}_{3}$ (purity 99,9\%) were mixed in equimolar amounts and grinded in an agate mortar for an hour, and then pressed into pellets with the diameter of $10 \mathrm{~mm}$. The heat treatment was performed inside the airtight apparatus with a confined internal space (Fig. 1). A sample in a crucible 1 was placed in the quartz reactor 2 mounted in the furnace 3 . Air was evacuated by the vacuum pump 4 out of the apparatus which was followed by refilling with argon. Oxygen partial pressure in the gas phase inside the apparatus was maintained and controlled by the oxygen cell 5 , which consists of the oxygen sensor 6 and the oxygen pump 7 . The oxygen cell was operated by the programmable oxygen pressure controller 8 . Since the thermal condition for each sample synthesis was tuned individually, but the oxygen cell worked at the limited tempearture range $600-900{ }^{\circ} \mathrm{C}$ (the optimal temperature is about $800{ }^{\circ} \mathrm{C}$ ) two temperature zonesin the apparatus were created: one for the oxygen cell (furnace 9) of the present study is the determination of conditions for preparation of $\mathrm{YbFe}_{2} \mathrm{O}_{4}$ at temperatures lower than $1200{ }^{\circ} \mathrm{C}$, and investigation of its physicochemical properties in the low-tempearture range.

and another for samples (furnace 3), retaining a common gas space. Syntheses of $\mathrm{YbFe}_{2} \mathrm{O}_{4-\delta}$ were carried out at $1090^{\circ} \mathrm{C}$ for 48 hours. It should be noted that it is the highest possible temperature that can be used in this apparatus because quartz was used as the reactor material. The value of oxygen partial pressure in the furnace 9 was set in the interval $\mathrm{pO}_{2}=10^{-11.04}-10^{-12.84}$ atm. It's worth to note that in the region of low oxygen pressures $\mathrm{pO}_{2}$ is defined by the equilibrium constant of reaction (1) and also depends on temperature [6]:

$$
\mathrm{H}_{2} \mathrm{O} \rightleftarrows 1 / 2 \mathrm{O}_{2}+\mathrm{H}_{2}
$$

Due to this fact the oxygen pressure in the furnace 3 differed from $p \mathrm{O}_{2}$ which was achieved and measured in the furnace 6 . The syntheses of samples in the furnace 3 at $1090^{\circ} \mathrm{C}$ were performed in the interval $p \mathrm{O}_{2}=10^{-11.04}-10^{-12.84} \mathrm{~atm}$. The circulation pump 10 was utilized to distribute the gas mixture with a controlled oxygen pressure evenly inside the apparatus. Manometervacuummeter 11 was used to measure the total gas pressure. The samples were quenched by pulling them out of the high temperature zone of the reactor into the space cooled by the flow of cold water.

The phase composition of quenced samples was determined by X-Ray diffraction (XRD) using a Shimadzu XRD7000C diffractometer $(\mathrm{Cu} \mathrm{Ka}$ radiation) in the range of angles $20^{\circ}<2 \theta<80^{\circ}$ with a step of $0.2^{\circ}$. The primary processing of diffraction data was performed with the software 
package for the diffractometer XRD-7000, and calculation of the unit cell parameters was carried out using the X-ray Diffraction Tabulated Process (RTP) program. Thermodynamic characteristics of $\mathrm{YbFe}_{2} \mathrm{O}_{4-\delta}$ in relatively low temperature range and the values of oxygen nonstoichiometry for the samples obtained at various oxygen partial pressure were determined with the vacuum circulation apparatus [7].

\section{Results and discussion}

According to the XRD data, the obtained $\mathrm{YbFe}_{2} \mathrm{O}_{4-\delta}$ samples were single-phase (Fig. 2). All of them possess rhombohedral structure (space group $R 3 m$ ). The unit cell parameters were in a good agreement with those collected from the database ICDD, PDF4, card No 01-070-1734 [8] (Fig. 2). The stability range for $\mathrm{YbFe}_{2} \mathrm{O}_{4}$ with respect to the oxygen partial pressure was determined at the fixed temperature $1090^{\circ} \mathrm{C}$. The decrease in oxygen pressure down to $p \mathrm{O}_{2}=10^{-12.84}$ atm leads to the partial de-

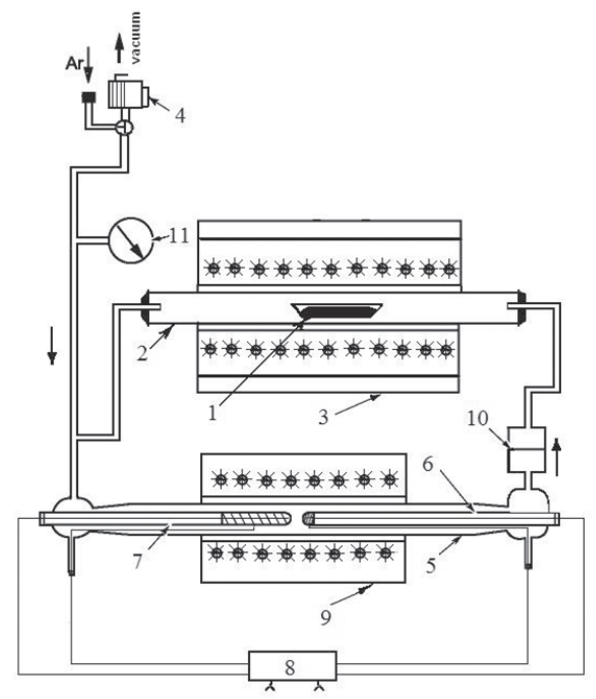

Fig. 1. A scheme of the apparatus for synthesis of materials at the required value of oxygen partial pressure. 1 - a crucible with a sample, 2 - quartz reactor, 3 - big furnace, 4 - vacuum forepump, 5 - oxygen cell,

6 - oxygen sensor, 7 - oxygen pump, 8 - oxygen partial pressure controller, 9 - small furnace, 10 - circulation pump, 11 - manometer-vacuum meter composition of initial $\mathrm{YbFe}_{2} \mathrm{O}_{4}$ oxide to $\mathrm{Yb}_{2} \mathrm{O}_{3}$ and $\mathrm{FeO}$ phases. On the other hand, when the oxygen partial pressure had been increased up to $\mathrm{pO}_{2}=10^{-11.04} \mathrm{~atm}, \mathrm{XRD}$ indicated that $\mathrm{YbFe}_{2} \mathrm{O}_{4}$ coexisted with the oxidized phases $\mathrm{YbFeO}_{3}$ and $\mathrm{Fe}_{3} \mathrm{O}_{4}$ (Fig. 3).

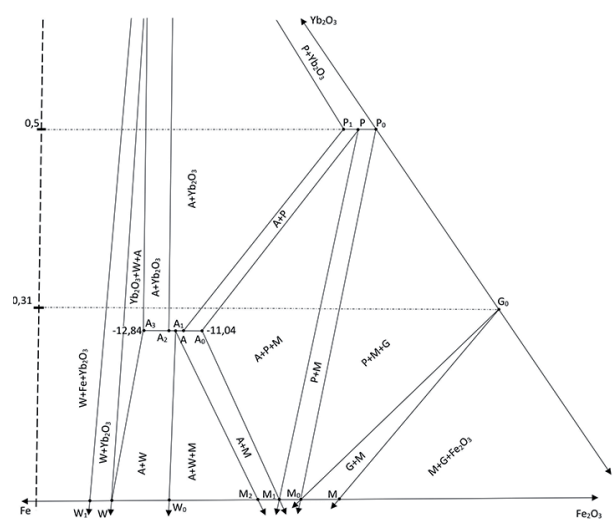

Fig. 3. A fragment of the phase diagram for the $\mathrm{Yb}-\mathrm{Fe}-\mathrm{O}$ system at $1090^{\circ} \mathrm{C}$. The phases are: $\mathrm{A}-\mathrm{YbFe}_{2} \mathrm{O}_{4 \pm \delta}, \mathrm{P}-\mathrm{YbFeO} \mathrm{O}_{3 \pm \delta}$,
$\mathrm{G}-\mathrm{Yb}_{3} \mathrm{Fe}_{5} \mathrm{O}_{12}, \mathrm{~W}-\mathrm{FeO}, \mathrm{M}-\mathrm{Fe}_{3} \mathrm{O}_{4}$

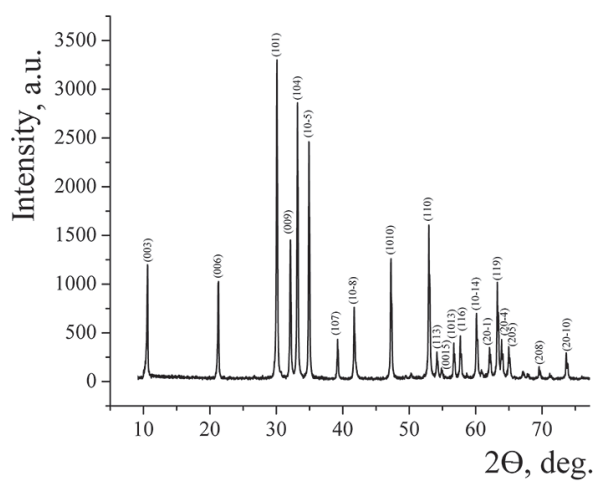

Fig. 2. Initial X-ray diffraction patterns of $\mathrm{YbFe}_{2} \mathrm{O}_{4}$ 
Thus, it was experimentally determined that in the $\mathrm{Yb}-\mathrm{Fe}-\mathrm{O}$ system at $1090{ }^{\circ} \mathrm{C}$ $\mathrm{YbFe}_{2} \mathrm{O}_{4-\delta}$ exists within the range of oxygen pressures $\mathrm{pO}_{2}=10^{-11.04}-10^{-12.84}$ atm. This result significantly widens the temperature range for $\mathrm{YbFe}_{2} \mathrm{O}_{4-\delta}$ stability, as compared to previous studies [2].

The absolute values of oxygen nonstoichiometry for samples prepared at various oxygen partial pressures were determined by means of gravimetric analysis via the hydrogen reduction of the samples to the stable simple oxides in the vacuum circulation setup as follows:

$$
\begin{gathered}
\mathrm{YbFe}_{2} \mathrm{O}_{4-\delta}+0.5 \mathrm{H}_{2}=0.5 \mathrm{Yb}_{2} \mathrm{O}_{3}+ \\
+2 \mathrm{FeO}+(0.5-\delta) \mathrm{H}_{2} \mathrm{O}
\end{gathered}
$$

The absolute value of oxygen nonstoichiometry was calculated using equation (3):

$$
\delta=\frac{M}{15.9994}-\frac{m \cdot M_{\mathrm{red}}}{m_{\mathrm{red}} \cdot 15.9994},
$$

where $M$ is the molecular weight of the studied oxide, $M_{\text {red }}$ is the total molecular weight of solid products in the reduction reaction with allowance for the stoichiometric coefficients, 15.9994 is the atomic weight of oxygen, $m_{\text {red }}$ is the weight of solid products after reduction reaction at the temperature of the experiment and $m$ is the sample weight. Detailed description of the procedure is given in [7]. A decrease of the oxygen partial pressure during synthesis results in formation of oxygen vacancies and consequent change of the $\mathrm{Fe}^{2+} / \mathrm{Fe}^{3+}$ ratio. At the same time the unit cell parameter $a$ increases while the oxygen partial pressure is reduced (Fig. 4, Table 1).

The obtained relationship between oxygen nonstoichiometry $\delta$, which is influenced by oxygen partial pressure and the unit cell parameter $a$ (Fig. 5), might be used as a criterion for oxygen nonstoichiometry $\delta$ estimation using only XRD results.

The measurements of $\mathrm{YbFe}_{2} \mathrm{O}_{4-\delta}$ thermodynamic stability have been carried out using the vacuum circulation apparatus by static method [7] in the temperature

\begin{tabular}{|c|c|c|c|}
\hline Sample & $\lg \left(p \mathrm{O}_{2}\right)(\mathrm{atm})$ at $1090^{\circ} \mathrm{C}$ & Unit cell parameter $a, c(\AA)$ & $\begin{array}{l}\text { Oxygen non- } \\
\text { stoichiometry } \delta\end{array}$ \\
\hline 1 & -11.4 & $\begin{array}{c}a=3.4506(4) \\
c=25.0773(19) \\
V=258.576\end{array}$ & 0.033 \\
\hline 2 & -11.6 & $\begin{array}{c}a=3.4519(4) \\
c=25.0655(20) \\
V=258.656\end{array}$ & 0.038 \\
\hline 3 & -11.8 & $\begin{array}{c}a=3.4528(4) \\
c=25.0865(20) \\
V=259.011\end{array}$ & 0.041 \\
\hline 4 & -12 & $\begin{array}{c}a=3.4538(4) \\
c=25.0855(21) \\
V=259.157\end{array}$ & 0.048 \\
\hline 5 & -12.2 & $\begin{array}{c}a=3.4547(4) \\
c=25.0715(20) \\
V=259.133\end{array}$ & 0.061 \\
\hline
\end{tabular}
range $700-910{ }^{\circ} \mathrm{C}$. The high temperature

Conditions of $\mathrm{YbFe}_{2} \mathrm{O}_{4-\delta}$ synthesis 
dissociation process of $\mathrm{YbFe}_{2} \mathrm{O}_{4}$ at low oxygen partial pressure within the range $p \mathrm{O}_{2}=$ $10^{-16.4}-10^{-20.8}$ atm as a first approximation was written neglecting oxygen nonstoichiometry of ytterbium ferrite and oxygen nonstoichiometry of simple iron oxide as follows:

$$
\begin{aligned}
& \mathrm{YbFe}_{2} \mathrm{O}_{4}=0.5 \mathrm{Yb}_{2} \mathrm{O}_{3}+ \\
& +2 \mathrm{FeO}+0.25 \mathrm{O}_{2}
\end{aligned}
$$

A linear function was fitted to the measured values of equilibrium oxygen partial pressure of the reaction (4) vs temperuture (filled point in Fig. 6), and the following equation was obtained:

$\lg \left(p \mathrm{O}_{2}, \mathrm{~Pa}\right)=11.78-27350 / T \pm 0.04$ (5)

Unfilled point 2 (Fig. 6) corresponds to the equilibrium oxygen partial pressure

\section{Conclusions}

It was found that $\mathrm{YbFe}_{2} \mathrm{O}_{4}$ can be prepared at $1090^{\circ} \mathrm{C}$ within the oxygen partial pressure range $p \mathrm{O}_{2}=10^{-11.04}-10^{-12.84} \mathrm{~atm}$. The obtained results allow specifying the low-temperature part of P-T-X diagram for the $\mathrm{Yb}-\mathrm{Fe}-\mathrm{O}$ system, which is very important from the practical point of view since it allows choosing the conditions for $\mathrm{YbFe}_{2} \mathrm{O}_{4}$ synthesis and usage. Using the static method in the vacuum circula-

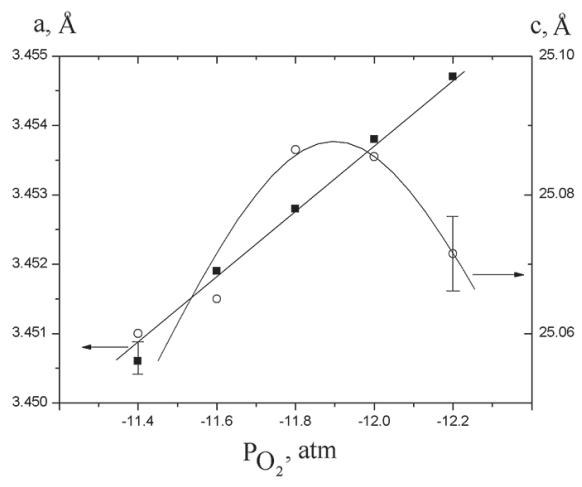

Fig. 4. Dependence of the unit cell parameter $a$ and $c$ on oxygen partial pressure for $\mathrm{YbFe}_{2} \mathrm{O}_{4 \pm \delta}$ synthesis measured at $1200^{\circ} \mathrm{C}$ by Kimizuka et al. [3]. One can observe good agreement of our results with those obtained earlier. Finally, Eq. (5) was recalculated to the standard Gibbs energy for reaction (4):

$$
\begin{aligned}
\Delta G_{T}^{o}= & 130.895-0.0564 T \pm \\
& \pm 0.99 \mathrm{~kJ} / \mathrm{mol}
\end{aligned}
$$

Since the coefficients in Eq. (6) can be treated as $\Delta H_{T}^{0}$ and $\Delta S_{T}^{0}$, respectively, for reaction (4), the changes of standard entropy and enthalpy for $\mathrm{YbFe}_{2} \mathrm{O}_{4}$ formation from elements can be calculated taken into account the values of the thermodynamic functions for the simple oxides' $\left(\mathrm{Yb}_{2} \mathrm{O}_{3}\right.$ and $\mathrm{FeO}$ ) formation [9,10]: $\Delta H_{f}^{0}\left(\mathrm{YbFe}_{2} \mathrm{O}_{4}\right)=$ $-1575.767 \mathrm{~kJ} / \mathrm{mol}, \Delta S_{f}^{0}=274.23 \mathrm{~kJ} / \mathrm{mol} / \mathrm{K}$.

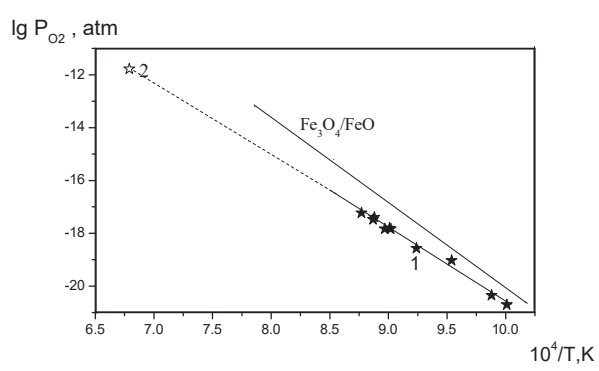

Fig. 6. Equilibrium oxygen partial pressure of $\mathrm{YbFe}_{2} \mathrm{O}_{4}$ dissociation (reaction 4) versus reciprocal temperature: 1 - our data, 2 -reported in [3]

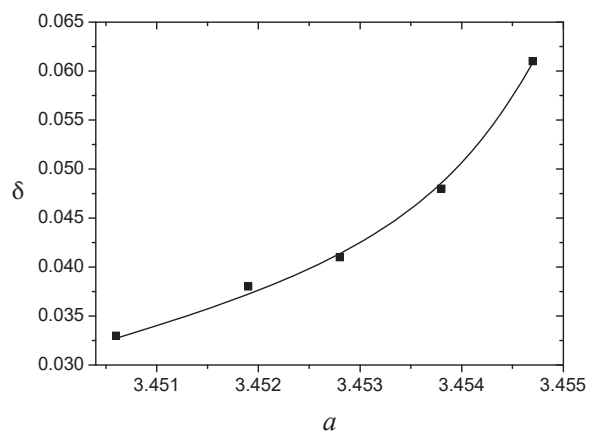

Fig. 5. Dependence of oxygen nonstoichiometry on unit cell parameter $a$ for $\mathrm{YbFe}_{2} \mathrm{O}_{4-\delta}$ 
tion apparatus, the decomposition oxygen partial pressure was measured. Finally, the changes of standard entropy and enthalpy of $\mathrm{YbFe}_{2} \mathrm{O}_{4}$ formation from elements in the temperature range $700-910{ }^{\circ} \mathrm{C}$ were calculated.

\section{Acknowledgements}

The study was done in accordance with the state quota for IMET UB RAS, theme No. 0396-2015-0075, using equipment of CCU "Ural-M".

\section{References}

1. Pyatakov AP, Zvezdin AK. Magnitoelektricheskiye materially I multiferroiki [Magnetoelectric materials and multiferroics]. Uspekhi fizicheskih nauk [Achievements in Physical Sciences]. 2012;182(6):593-620. Russian. DOI: 10.3367/ UFNr.0182.201206b.0593.

2. Kimizuka N, Katsura T. The Standard Free Energy of Formation of $\mathrm{YbFe}_{2} \mathrm{O}_{4}$, $\mathrm{Yb}_{2} \mathrm{Fe}_{3} \mathrm{O}_{7}, \mathrm{YbFeO}_{3}$, and $\mathrm{Yb}_{3} \mathrm{Fe}_{5} \mathrm{O}_{12}$ at $1200{ }^{\circ} \mathrm{C}$. J Solid State Chem. 1975;15:151-7. DOI: 10.1016/0022-4596(75)90238-8.

3. Kimizuka N, Takenaka A, Sasada Y, Katsura T. A series of new compounds $\mathrm{A}^{3+} \mathrm{Fe}_{2} \mathrm{O}_{4}(\mathrm{~A}=\mathrm{Ho}, \mathrm{Er}, \mathrm{Tm}, \mathrm{Yb}$, and Lu). Solid State Commun. 1974;15:1321-3. DOI: 10.1016/0038-1098(74)91372-6.

4. Katsura T, Sekine T, Kitayama K, Sugihara T, Kimizuka N. Thermodynamic Properties of Fe-Lanthanoid-O Compounds at High Temperatures. J Solid State Chem. 1978;23:43-57.Doi.org/10.1016/0022-4596(78)90052-X.

5. Yankin AM, Vedmid' LB. inventors; Institute of Metallurgy UB RAS, assignee. Isobaric console to synchronous thermoanalyzer. Russian Federation patent RU88452. 2009 Nov 11. Russian.

6. Chufarov GI, Men' AN, Zhuravleva MG, Balakirev VF, Shchepyotkin AA. Termodinamika processov vosstanovleniya okislov metallov [Thermodynamics of metal oxides' reduction processes]. Moscow: Metallurgy; 1970. 480 p. Russian.

7. Yankin AM, Balakirev VF, Vedmid' LB, Fedorova OM. A Static Method for Studying Heterogeneous Equilibria. Russ J Phys Chem. 2003;77(11):1899-1902.

8. Kato K, Kawada I, Kimizuka N, Katsura T. Die Kristallstruktur von $\mathrm{YbFe}_{2} \mathrm{O}_{4}$. Zeitschrift für Kristallographie. 1975;141:314-20. DOI: 10.1524/zkri.1975.141.3-4.314.

9. Portnoy KI, Timofeeva NI. Kislorodnye soedineniya redkozemelnyh elementov [Oxygen compounds of rare-earth elements]. Moscow: Metallurgy; 1986. 480 p. Russian.

10. Tret'yakov Yu D. Khimiya nestekhiometricheskikh okislov [Chemistry of nonstoichiometric oxides]. Moscow: MGU; 1974. 364 p. Russian. 